\title{
MEDIA KOMUNIKASI PEMASARAN PADA INSTITUSI GEREJA (ANALISIS TERHADAP PERAN INSTAGRAM)
}

\author{
Stephen Pratama ${ }^{1}$, Chairy Chairy ${ }^{2}$ \\ ${ }^{1}$ Program Studi Magister Manajemen, Universitas Tarumanagara \\ Email: Stephen.pratama93@yahoo.co.id \\ ${ }^{2}$ Fakultas Bisnis, President University, Bekasi, Indonesia \\ Email: chairy@president.ac.id
}

Masuk : 14-04-2020, revisi: 25-04-2020, diterima untuk diterbitkan : 25-04-2020

\begin{abstract}
ABSTRAK
Penelitian ini mengeksplorasi komunikasi pemasaran yang dilakukan Gereja Mawar Sharon melalui Instagram kepada Jemaatnya yang berada di Jakarta. Instagram dipilih karena merupakan salah satu media sosial yang paling banyak penggunanya di Indonesia. Media sosial ini digunakan untuk menghubungkan Gereja Mawar Sharon dengan pengikutnya (followers). Penelitian yang merupakan penelitian deskriptif ini menggunakan analisis sumber atau studi komunikator. Hasil penelitian menunjukan bahwa tidak terdapat hambatan yang ditemui oleh Gereja Mawar Sharon ketika menggunakan Instagram sebagai alat komunikasi pemasaran untuk eventnya. Selain mudah digunakan dan berbiaya murah, Instagram dapat dengan mudah menyesuaikan fiturnya sehingga menjadi lebih menawan dan efektif sesuai tujuan komunikasi pemasaran yang ingin dicapai. Dengan memanfaatkan Instagram, dimungkinkan adanya interaksi yang erat antara Gereja Mawar Sharon dengan para pengikutnya.
\end{abstract}

Kata Kunci: Instagram, Media komunikasi, Institusi Gereja

\section{ABSTRACT}

This study explored the marketing communication process carried out by Mawar Sharon Church through Instagram accounts to followers in Jakarta. Instagram is used because it is one of the most favorite social media in Indonesia. This research is a descriptive research that uses source analysis or communicator studies as the basis of research. The research result showed that there were no obstacles encountered by the Mawar Sharon Church while utilizing Instagram as a marketing communication tool for marketing its events. Apart from ease of use and low cost, Instagram can update all features available to make it more attractive and beneficial for its users. Through Instagram, there is a closed interaction between Mawar Sharon Church and the followers.

Keywords: Instagram, Communication media, Church Institution.

\section{PENDAHULUAN}

\section{Latar Belakang}

Internet sangat membantu berbagai organisasi, baik dalam kegiatan merancang dan melaksanakan strategi bisnis maupun dalam eksekusi program komunikasi pemasaran organisasi tersebut (Morissan, 2010). Setiap organisasi yang dapat mengakses internet melalui berbagai perangkat akan langsung menjadi salah satu peserta dalam jaringan komunikasi global. Organisasi dapat memanfaatkan akses internet ini untuk berbagai kegiatan termasuk kegiatan komunikasi yang telah menjadi salah satu kegiatan penting dalam kehidupan organisasi. Pemanfaatan komunikasi misalnya untuk kegiatan pemasaran dalam suatu organisasi, tidak dapat dipungkiri telah menjadi ujung tombak organisasi dalam menghasilkan revenue.

Seperti diketahui, pemanfaatan komunikasi dalam kegiatan pemasaran dikenal sebagai "komunikasi pemasaran" yang dahulu sering disebut sebagai "promosi". Kotler dan Keller (2016) mengatakan, komunikasi pemasaran adalah suatu sarana yang digunakan perusahaan dalam menyampaikan informasi, melakukan persuasi, dan mengingatkan konsumen baik secara langsung maupun tidak langsung mengenai produk atau jasa yang dihasilkannya. Dengan demikian komunikasi pemasaran merupakan usaha perusahaan dalam mengenalkan produk dan jasanya, serta menjadi alat untuk membangun hubungan pelanggan. Komunikasi pemasaran 
dapat mengadopsi berbagai kegiatan seperti periklanan, penjualan pribadi, penjualan langsung, penjualan melalui event, promosi penjualan, publisitas atau hubungan masyarakat, penjualan dari mulut ke mulut, dan berbagai bentuk lainnya yang digunakan perusahaan untuk keberhasilan pemasarannya.

Pertiwi, W. K.(2020) Data terbaru pengguna internet di Indonesia tercatat sebanyak 175,4 juta dari 272,1 juta penduduk Indonesia atau sekitar 64\%-nya. Sejalan dengan berkembangnya teknologi informasi dan komunikasi, munculah media baru yaitu media online. Berbagai organisasi kemudian memanfaatkan kemudahan yang ditawarkan media online, sehingga akhirnya media online ini menjadi "dunia kedua" dalam kehidupan suatu organisasi. Salah satu bentuk media online yang popular saat ini adalah media sosial. Terdapat berbagai fungsi media sosial yaitu misalnya sebagai sarana interaktif, sumber informasi, perangkat untuk membangun hubungan pelanggan, berbagi ide, hingga alat pemasaran produk dan jasa suatu organisasi.

\section{Instagram}

Kegiatan pemasaran saat ini banyak memanfaatkan media sosial, salah satunya adalah dengan menggunakan Instagram. Media sosial ini dapat digunakan untuk saling berbagi foto dan saling menyebarkannya melalui jaringan sosial. Haryanto, A. T. (2020) Berbagai media sosial telah berkembang di Indonesia, dan akhirnya membawa Instagram sebagai salah satu media sosial yang paling populer. Bersama dengan Youtube, Whatsapp, Facebook, dan Twitter, Instagram merupakan lima besar aplikasi media social yang digunakan masyarakat Indonesia.

Mempertimbangkan populernya Instagram, media sosial ini kemudian banyak diadopsi oleh para pemasar dalam mendukung memasarkan produk dan jasa mereka. Keampuhan Instagram perlu juga didukung dengan pemasaran offline, dengan demikian terjadi sinergi antara pemasaran online dan offline, yang akibatnya proses adopsi konsumen dapat terjadi dengan lebih cepat.

Generasi muda terutama mahasiswa merupakan pengguna utama Instagram untuk pemasaran bisnis secara online. Mereka dikenal sebagai generasi yang kreatif dan kritis serta cepat mengadopsi suatu inovasi baru, sehingga mereka dapat dengan cepat dan mudah memanfaatkan Instagram untuk berbagai keperluan, termasuk dalam pemasaran dan penyelengaraan suatu event. Berbagai event yang disukai kalangan muda diantaranya yang berkaitan dengan fashion dan hobi mereka.

Instagram yang pada dasarnya merupakan aplikasi yang terutama dimanfaatkan untuk berbagi foto dan film pendek, adalah afiliasi dari Facebook yang dengan demikian dapat diakses teman di Facebook untuk juga menjadi teman di Instagram. Seperti diketahui, Instagram yang merupakan media untuk berbagi foto dan film pendek dikembangkan oleh Burbn, Inc., yang pada mulanya adalah suatu organisasi bisnis yang bergerak di bidang pengembangan aplikasi untuk telepon selular. Instagram kemudian banyak dimanfaatkan untuk memasarkan berbagai produk dan jasa karena kemampuannya untuk menerima dan menyebarkan foto dan film pendek yang menampilkan berbagai produk dan jasa yang akan dipasarkan. (Rahmawati, 2016)

Perkembangan yang cepat dari Instagram kemudian memicu menjamurnya pemasaran event dengan memanfaatkan Instagram sebagai media komunikasi pemasarannya. Demikian juga, Institusi Gereja seperti Gereja Mawar Sharon (GMS) juga memanfaatkan keunggulan Instagram. GMS merupakan salah satu gereja Karismatik yang memberikan pelayanan berdasarkan kuasa Kristus. Misi GMS adalah "sebagai gereja sel yang Apostolik dan Profetik dengan 1.000 gereja lokal yang kuat dan 1.000.000 murid Kristus". GMS Jakarta memiliki followers Instagram 
sebanyak lebih dari 17.400. GMS menyelenggarakan event untuk kalangan Profesional Muda (ProM) yaitu orang-orang yang sudah bekerja dan berpenghasilan sendiri dengan rentang umur 20-30 tahun.

Artikel ini membahas tentang proses komunikasi dengan menggunakan Instagram sebagai media komunikasi pemasaran oleh Intitusi Keagamaan dalam hal ini GMS. Sejauh ini penelitian yang membahas penggunaan Instagram sebagai alat komunikasi pemasaran pada institusi Gereja sangat terbatas. Contohnya, Kusuma dan Sugandi (2018) memaparkan penggunaan Instagram untuk komunikasi pemasaran, namun dalam hal ini untuk pemasaran makanan yaitu donat. Contoh lainnya adalah Kurniawan (2017) yang memaparkan pemanfaatan media sosial Instagram untuk komunikasi pemasaran produk batik. Tani, Boham, \& Tangkudung (2016) membahas penggunaan sosial media di lingkungan Gereja yang mencakup google, gmail, path, facebook, instagram, bbm, dan twitter. Namun penggunaan media sosial ini lebih pada untuk hiburan generasi muda. Penelitian terbaru yang dilakukan oleh Gaber, Wright, dan Kooli (2019) di Mesir juga memperlihatkan aspek positif yang dimiliki Instagram yaitu sikap terhadap iklan Instagram yang semakin kuat di berbagai kalangan konsumen. Sikap terhadap Instagram ini dipengaruhi oleh aspek informatif, hiburan, kredibilitas, dan rendahnya iritasi dari iklan di Instagram.

Seiring perkembangan zaman, saat ini tersedia media komunikasi modern yang berpengaruh terhadap proses komunikasi. Pengaruh tersebut merupakan suatu timbal balik yang terjadi dalam proses komunikasi. Adanya teknologi komunikasi interaktif, suatu organisasi selain akan bertanya, "Bagaimana dalam melayani para pelanggan kita?" namun juga perlu bertanya, "Bagaimana membuat pelanggan kita mudah berkomunikasi dengan kita?" (Kotler dan Keller, 2016). Adapaun proses komunikasi bertujuan mendapatkan efek dari proses penyampaian isi pemberitahuan atau informasi itu dapat berupa perubahan sikap, perubahan pendapat, dan perubahan perilaku" (Effendy, 2009). Agar efektifnya suatu komunikasi, pemasar perlu menguasai proses komunikasi. Dalam proses komunikasi, terdapat sembilan elemen. Elemen tersebut pada Gambar 1 dibawah ini (Hermawan, 2012):

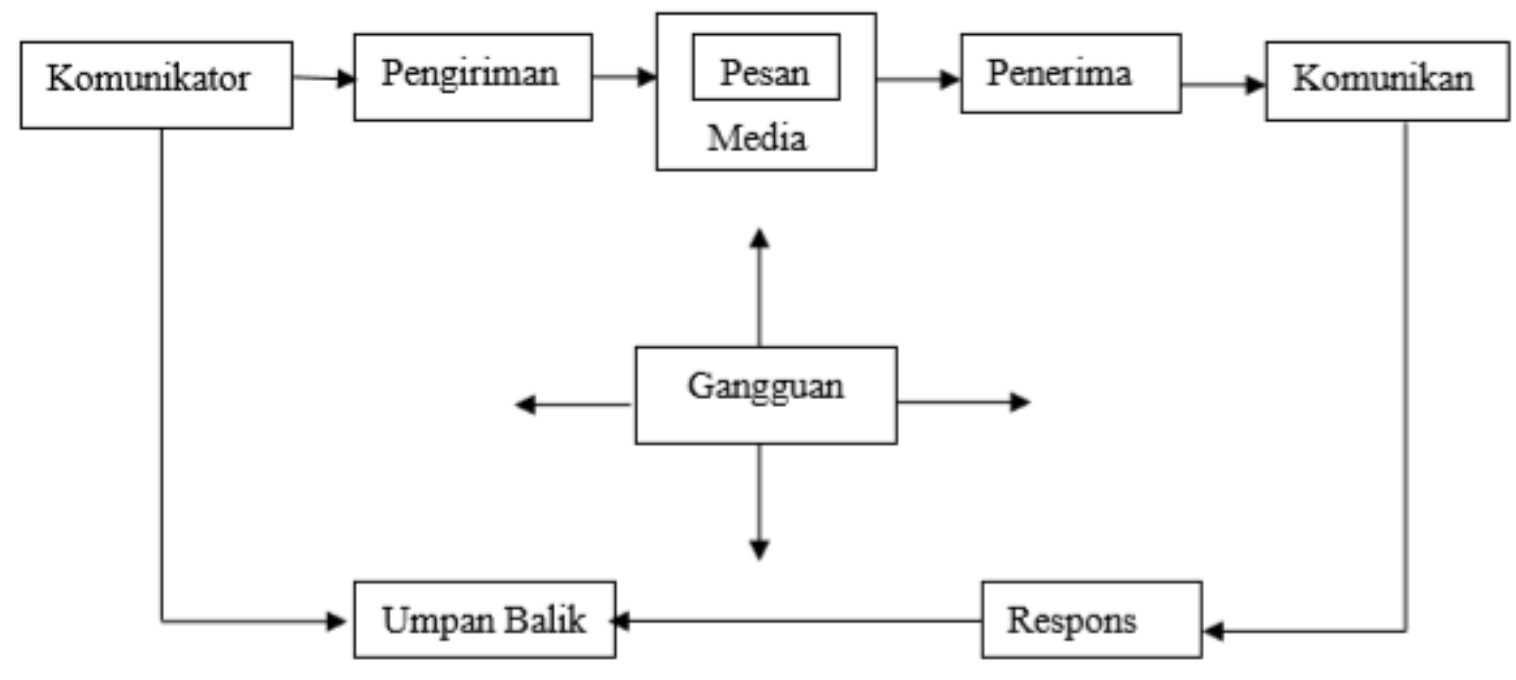

Gambar 1. Model Komunikasi

Sumber: Hermawan, 2012 
1. Komunikator (sender) mengirimkan pesan kepada pihak lain. Bentuk pesan dapat berupa bahasa atau simbol yang dipahami bersama.

2. Pesan (message) ini disalurkan melalui suatu media.

3. Proses pengkodean (encoding) adalah proses mengubah suatu pesan menjadi kode yang dapat dioptimasi dalam pengiriman pesan.

4. Media (channel) adalah alat yang digunakan dalam penyampaian pesan dari komunikator ke penerima pesan.

5. Interpretasi kode (decoding) adalah proses menterjemahkan kode atau simbol agar dapat dipahami dengan baik oleh penerima pesan.

6. Komunikan (receiver) adalah pihak yang menerima pesan kemudian menginterpretasi pesan tersebut.

7. Tanggapan (response) merupakan tindakan yang diperlihatkan oleh penerima pesan setelah pesan diterimanya.

8. Umpan balik (feedback) adalah tindakan yang diperlihatkan setelah menerima pesan sebagai wujud dari dipahami atau tidaknya pesan dimaksud.

9. Gangguan (noise) dalam komunikasi adalah sesuatu yang mendistorsi pesan. Gangguan ini dapat menghalangi baik penerima maupun sumber pengirim pesan. Gangguan terjadi apabila pesan yang diterima diartikan berbeda dengan maksud pesan.

Model universal komunikasi di atas diadaptasi oleh suatu organisasi dalam melakukan pemasaran event yang ditujukan kepada konsumen targetnya. Karenanya, dalam memasarkan event, sembilan elemen dalam komunikasi berperan sebagai berikut:

1. Sender adalah organisasi yang menyelenggarakan event dan ingin mempromosikannya kepada targetnya. Suatu organisasi dapat memanfaatkan jasa pihak ketiga seperti biro iklan atau melakukannya sendiri ketika akan memasarkan eventnya.

2. Encoding merupakan kegiatan mengubah ide tentang penyelengaraan event menjadi suatu karya yang menarik.

3. Message adalah informasi tentang event yang akan diselenggarakan.

4. Media adalah berbagai saluran komunikasi yang mungkin diadopsi termasuk media sosial Instagram.

5. Decoding adalah bagaimana penerima pesan tentang event menterjemahkan pesan yang diterimanya.

6. Receiver adalah target pasar yang dalam hal ini adalah Jemaat.

7. Response adalah tanggapan penerima pesan atas informasi tentang event yang diterimanya.

8. Umpan balik (feedback) adalah tanggapan target pasar yang menghadiri event dari suatu organisasi. Apakah pelanggan tersebut puas dengan event yang diselenggarakan oleh organisasi tersebut.

9. Noise dapat berupa pelaku yang serupa yang juga mengadopsi pendekatan yang sama sehingga target pasar menerima terlalu banyak pesan yang serupa. Disini diperlukan strategi komunikasi yang efektif agar penerima pesan dapat memperoleh informasi yang akurat.

Ketika berkomunikasi dengan masyarakat luas, perlu diperhatikan konsep komunikasi massa. Menurut Susanto (2018), komunikasi massa merupakan pesan yang melibatkan banyak orang atau penerima pesan. Selain itu, komunikasi massa melibatkan penerima pesan yang beragam dan tersebar. Dengan demikian terdapat karakteristik utama dalam komunikasi massa yaitu penerima pesan yang keragaman, anonym, dan tersebar. Karakteritisk utama ini perlu diperhatikan ketika memasarkan event. 


\section{Bisnis Online}

Dalam kegiatan pemasaran yang menggunakan media sosial seperti Instagram, perlu juga diketahui karakteristik bisnis online. Bisnis online adalah aktivitas bisnis yang dilakukan dengan menggunakan internet untuk menghasilkan pendapatan. Istilah yang sering digunakan untuk menggambarkan kegiatan penjualan melalui internet adalah electronic commerce. Kalakota dan Whinston (1997) dalam Suyanto (2003) mendefiniskan electronic commerce dari empat perspektif yaitu perspektif komunikasi, proses bisnis, layanan, dan online. Perspektif komunikasi berkaitan dengan pemanfaatan jaringan komputer dan elektronik untuk kepentingan transaksi. Perspektif proses bisnis berkaitan dengan penggunaan teknologi untuk kelancaran transaksi. Perspektif layanan berkaitan dengan peningkatan mutu produk dan kepuasan pelangggan. Perspektif online berkaitan dengan kapasitas internet untuk menopang transaksi.

Adapun alasan untuk melakukan bisnis melalui e-commerce (Morissan, 2010) terutama karena jangkauan audien yang luas hingga ke seluruh dunia, dimungkinkan untuk melakukan komunikasi dua arah, dimungkinkan untuk menjangkau konsumen secara langsung, terdapat kemudahan dan kecepatan dalam melakukan penyesuaian informasi, dimungkinkan untuk meningkatkan kepuasan konsumen karena jam operasi yang panjang hingga 24 jam, dimungkinkan memperoleh umpan balik dalam waktu cepat dari konsumen, memiliki peran sebagai saluran distribusi alternatif, dan biaya operasional yang rendah.

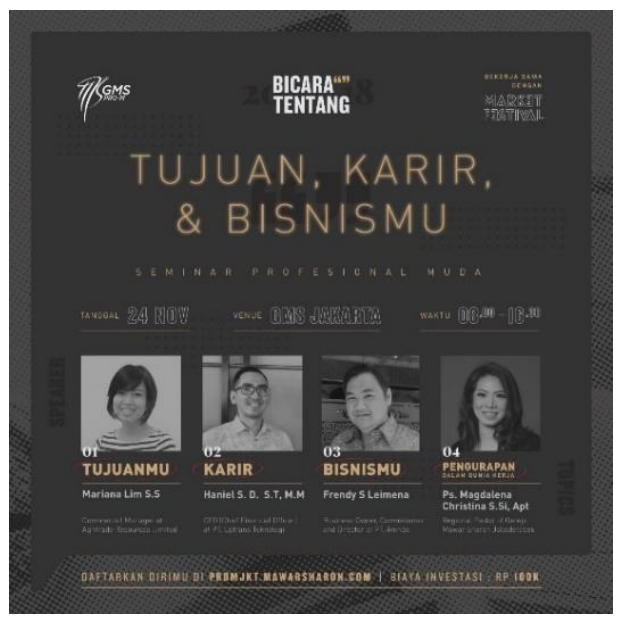

Gambar 2. Leaflet Seminar

Sumber: GMS

Adapun contoh event yang diselenggarakan oleh GMS adalah "Bicara Tentang Tujuan, Karir, dan Bisnismu" pada 24 November 2018. Tujuan dari diadakanya acara ini adalah melengkapi peserta seminar dalam mengetahui tujuan hidup, karir mereka dalam perusahaan, bisnis mereka untuk menjadi seorang enterpreneur serta pengurapan di dalam hidup mereka dengan menampilkan 4 pembicara (Gambar 2).

\section{METODE PENELITIAN}

Penelitian ini merupakan penelitian deskriptif dengan maksud untuk mengumpulkan informasi nyata agar dapat yang menggambarkan suatu fenomen dengan tepat (Kriyantono, 2008). Analisis yang digunalan adalah analisis sumber atau studi komunikator. Dalam hal ini komunikator sebagai individu maupun institusi Objek dalam penelitian ini adalah penggunaan Instagram untuk komunikasi pemasaran event yang dilakukan oleh GMS. Populasi dalam penelitian ini adalah seluruh jemaat GMS Jakarta dengan rentang usia 20-30 tahun yang berdasarakan data yang pernah tercatat berjumlah sekitar 1500 Jemaat. 


\section{HASIL DAN PEMBAHASAN}

Mengacu pada bagan proses komunikasi, maka proses komunikasi yang terjadi untuk penawaran event oleh GMS adalah sebagai berikut:

1. Komunikator pada GMS adalah admin Pengelola Medsos yang merupakan komunikator untuk segala aktivitas bisnis online yang dilakukan GMS, termasuk kegiatan pemasaran event yang akan di tawarkan kepada para Jemaat.

2. Proses pengiriman pesan atau proses encoding, dimana ide maupun gagasan akan ditransformasikan ke dalam berbagai bentuk kode pesan atau informasi kreatif agar dapat menarik perhatian penerima pesan atau Jemaat. Proses encoding dilakukan Komunikator melalui kegiatan mem-posting berbagai gambar atau foto dari event yang ditawarkan dengan menggunakan media sosial Instagram.

3. Pesan yang di sampaikan GMS pada Instagram adalah berupa event yang mereka desain dan tawarkan kepada Jemaat.

4. Media yang di gunakan oleh GMS adalah Instagram, alasan GMS memilih Instagram karena keunggulan Instagram seperti yang telah dijelaskan di atas.

5. Proses penerimaan pesan atau proses decoding pada GMS adalah persepsi Jemaat yang timbul setelah melihat pesan yang di posting pada Instagram GMS. Jemaat biasanya memberikan komentar pada event yang telah di posting oleh GMS.

6. Komunikan pada GMS merupakan followers pada akun Instagram GMS. Sejauh ini followers GMS mencapai lebih dari 71.200 Jemaat pada tahun 2018.

7. Respon yang berasal dari Jemaat pada proses komunikasi pemasaran GMS seperti yang telah diuraikan sebelumnya berupa pertanyaan mengenai informasi dari suatu event. Segala jenis tanggapan ini diajukan kepada GMS dengan memberi komentar pada posting-an gambar event di Instagram. Segala respon Jemaat pelanggan yang dapat di tanggapi Komunikator maupun adminnya akan mengarah pada proses pendaftaran event apabila Jemaat tertarik untuk menghadiri event tersebut, yang selanjutnya diikuti dengan pembayaran kepesertaan melalui transfer ke rekening bank GMS. Setelah transasksi berhasil, Komunikator akan mengirim barcode event.

8. Umpan balik, beberapa Jemaat dapat saja memberikan tanggapan dan saran atas event yang diselenggarakan.

9. Gangguan yang timbul dalam proses komunikasi yang dapat mengurangi efektivitas penyampaian informasi kepada Jemaat. Segala pesan yang ingin disampaikan melalui Instagram umumnya berupa gambar. Untuk itu sangat dibutuhkan koneksi internet yang baik agar pesan dapat sampai kepada komunikan dengan baik.

Dalam hal ini, GMS melakukan interkasi secara langsung dengan para pelanggan yaitu followers-nya pada akun Instgram. GMS juga secara tidak langsung menciptakan masyarakat sendiri yaitu followers pada akun Instagram tersebut. Dengan demikian terdapat peran Instagram yang vital dalam pemasaran event yang dilakukan oleh GMS. Peran tersebut mencakup sebagai saluran untuk berkomunikasi dengan Jemaatnya yaitu antara lain pengiriman pesan gambar dan film pendek tentang event, dilanjutkan dengan penerimaan dan pengelelolaan respon dari Jemaat, sampai akhirnya penyampaian umpan balik dari Jemaat. Walaupun tidak semua fitur digunakan Komunikator dalam proses pemasaran yaitu terbatas hanya IG Story dan posting foto saja.

Peran Instagram pada bisnis online GMS dapat dikatakan sukses terlihat dengan pencapaian jumlah pendaftar dalam seminar "Bicara Tentang Tujuan, Karir, dan Bisnismu." Dari Jemaat sejumlah 1500 Jemaat, terdata pada hari H terdapat 783 total pendaftar hadir sebanyak 658 orang ditambah dengan 205 orang yang berasal dari luar GMS. Berdasarkan data internal yang terkumpul, terjadi kenaikan pendaftar dari hari ke hari hingga menjelang hari $\mathrm{H}$ seminar. 
Keberhasilan ini sejalan dengan keampuhan Instagram sebagai alat untuk komunikasi pemasaran pada berbagai sektor seperti yang dilaporkan oleh Kurniawan (2017) pada bisnis batik, Kusuma dan Sugandi (2018) pada produk makanan donat. Berhasilnya peran Instagram sebagai alat komunikasi pemasaran di Institusi Gereja juga sejalan dengan penelitian Tani et al (2016) yang melaporkan maraknya penggunaan berbagai varian media sosial di kalangan anak muda Gereja.

\section{KESIMPULAN DAN SARAN}

\section{Kesimpulan}

Berdasarkan uraian di atas beberapa kesimpulan dapat disajikan sebagai berikut:

1. Tidak diragukan Instagram efektif digunakan untuk menyebarkan informasi yang berhubungan dengan suatu event dari suatu institusi keagamaan

2. Postingan dalam Instagram memudahkan Jemaat memperoleh informaasi dan dapat membuat mereka tertarik menghadiri suatu cara yang diselenggarakan institusi keagamaan.

3. Dalam kasus GMS, terbukti dengan menggunakan Instagram, acara seminar yang diselenggarkan mampu menarik sejumlah peserta sesuai harapan.

\section{Saran}

Saran yang layak disampaikan berdasarkan uraian di atas adalah sebagai berikut:

1. Mempertimbangkan efektifitas Instagram, perlu pemanfaatan Instagram seoptimal mungkin pada berbagai kegiatan keagamaan terutama apabila target audiensnya adalah kalangan muda.

2. Karena Instagram diperuntukan berkomunikasi dengan orang lain yang berada di berbagai tempat yang jaraknya sangat mungkin berjauhan, maka penggunaan Instagram perlu dilengkapi dengan interaksi tatap muka untuk memperjelas tujuan komunikasi yang diinginkan.

\section{REFERENSI}

Effendy, O. U. (2009). Ilmu komunikasi: Teori dan praktek. Bandung: Remaja Rosdakarya.

Gaber, H.R., Wright, L.T., \& Kooli, K. (2019). Consumer attitudes towards Instagram advertisements in Egypt: The role of the perceived advertising value and personalization, Cogent Business and Management, 6: 1618431

Hermawan, A. (2012). Komunikasi pemasaran. Jakarta: Erlangga.

Kotler, P., \& Keller, K.L. (2016). Marketing management, $15^{\text {Th }}$ edition, Harlow, United Kingdom: Pearson.

Kriyantono, R. (2008). Teknik praktis riset komunikasi. Jakarta: Kencana.

Kurniawan, P. (2017). Pemanfaatan media sosial Instagram sebagai komunikasi pemasaran modern pada Batik Burneh, Kompetensi, 11(2), 217-225

Kusuma, D.F., \& Sugandi, M.S. (2018). Strategi pemanfaatan Instagram sebagai media komunikasi pemasaran digital yang dilakukan oleh Dino Donuts, Jurnal Manajemen Komunikasi, 3(1), 18-33.

Morissan. (2010). Periklanan komunikasi pemasaran terpadu. Jakarta: Kencana Prenadamedia Group.

Pertiwi, W. K.(2020). "Penetrasi Internet di Indonesia Capai 64 Persen”. diakses 23 Maret 2020 dari https://tekno.kompas.com/read/2020/02/20/14090017/penetrasi-internet-di-indonesiacapai-64-persen.

Rahmawati, D. (2016). Pemilihan dan pemanfaatan Instagram sebagai media komunikasi pemasaran online (Studi desktiptif kualitatif pada akun Instagram @ FreezyBrowniezz). Skripsi. Fakultas Ilmu Sosisal dan Humaniora, Universitas Islam Negri Sunan Kalijaga, Yogyakarta. 
Haryanto, A. T. (2020). "Ada 175,2 Juta Pengguna Internet di Indonesia". diakses 23 Maret 2020 dari https://inet.detik.com/cyberlife/d-4907674/riset-ada-1752-juta-penggunainternet-di-indonesia.

Susanto, E. H. (2018). Komunikasi massa: Teori dan praktek dalam penyampaian gagasan, Jakarta: Mitra Wacana Media.

Suyanto, M. (2003). Periklanan pada e-Commerce perusahaan top dunia. Yogyakarta: ANDI.

Tani, F., Boham, A., \& Tangkudung, P. (2016). Kajian peran media online bagi pemuda di Gereja Advent Walantakan Kecamatan Langowan Barat, Acta Diurna, 5(3), Tani. 